\title{
FHIT down-regulation was inversely linked to aggressive behaviors and adverse prognosis of gastric cancer: a meta- and bioinformatics analysis
}

\author{
Hua-Chuan Zheng ${ }^{1}$ and Li-Li Liu ${ }^{2}$ \\ ${ }^{1}$ Department of Experimental Oncology and Animal Center, Shengjing Hospital of China Medical University, Shenyang \\ 110004, China \\ ${ }^{2}$ Department of Pathology, Harbin Medical University-Daqing, Daqing 163319, China \\ Correspondence to: Hua-Chuan Zheng, email: zheng_huachuan@hotmail.com
}

Keywords: FHIT, gastric cancer, meta-analysis, bioinformatics analysis

Received: August 01, 2017 Accepted: October 03, $2017 \quad$ Published: November 03, 2017

Copyright: Zheng et al. This is an open-access article distributed under the terms of the Creative Commons Attribution License 3.0 (CC BY 3.0), which permits unrestricted use, distribution, and reproduction in any medium, provided the original author and source are credited.

\begin{abstract}
FHIT (fragile histine triad) acts as diadenosine P1, P3-bis (5'-adenosyl)triphosphate adenylohydrolase involved in purine metabolism, and induces apoptosis as a tumor suppressor. We performed a systematic meta- and bioinformatics analysis through multiple online databases up to March 14, 2017. The down-regulated FHIT expression was found in gastric cancer, compared with normal mucosa and dysplasia $(p<0.05)$. FHIT expression was negatively with depth of invasion, lymph node metastasis, distant metastasis, TNM staging and dedifferentiation of gastric cancer $(p<0.05)$. A positive association between FHIT expression and favorable overall survival was found in patients with gastric cancer $(p<0.05)$. According to KaplanMeier plotter, we found that a higher FHIT expression was negatively correlated with overall and progression-free survival rates of all cancer patients, even stratified by aggressive parameters $(p<0.05)$. These findings indicated that FHIT expression might be employed as a potential marker to indicate gastric carcinogenesis and subsequent progression, even prognosis.
\end{abstract}

\section{INTRODUCTION}

FHIT (fragile histine triad) is also known as human accelerated region 10 and encompasses the common fragile site FRA3B at 3p14.2, where carcinogen-induced damage can lead to translocations and aberrant transcripts of this gene. It spans more than $1.5 \mathrm{mb}$ as the second largest human gene, and encodes a 17kd diadenosine P1, P3-bis (5'-adenosyl)- triphosphate adenylohydrolase involved in purine metabolism. Moreover, FHIT protein inhibits cell proliferation and induces apoptosis as a tumor suppressor, which is independent of its hydrolase activity [1]. FHIT upregulates the expression of thymidine kinase 1, resulting in dNTP imbalance, and spontaneous replication stress that leads to chromosomal aberrations, allele copy number variations, insertions/deletions, and singlebase substitutions [2]. FHIT acts as a checkpoint in cell proliferation mediated by activated tyrosine kinase receptors that recruit src [3]. Src family tyrosine kinases can phosphorylate FHIT at tyrosine 114 (Y114) within the unstructured loop C-terminal of the catalytic site, which induces Caspase- dependent apoptosis of lung cancer cells by decreasing survivin expression and Akt activity [4]. FHIT also associates with the lymphoid enhancer-binding factor $1 / \mathrm{T}$ cell factor/ $\beta$-catenin complex by directly binding to $\beta$-catenin, and repressing the transcription of cyclin D1, axin2, MMP-14, and survivin [5]. FHIT delocalizes Annexin a4 from plasma membrane to cytosol and sensitizes lung cancer cells to paclitaxel [6]. Semba et al. [7] found that FHIT overexpression down-regulated cyclophilin A expression to prevent cyclophilin A-induced up-regulation of cyclin D1, Cdk4, resulting in $\mathrm{G}_{1}-\mathrm{S}$ progression. FHIT gene expression is repressed in breast cancer cells by mitogenic signaling through $\mathrm{PI} 3 \mathrm{~K} / \mathrm{Akt} / \mathrm{FOXO}$ pathway [8], which promots MHC-I down-regulation and allows escape from immunosurveillance [9] and 
enhances expression of oxidative stress response genes after exposure to cigarette smoke extract, including cytoprotective enzyme heme oxygenase 1 [10].

The transcription deletion of FHIT was detectable in intrahepatic cholangiocellular carcinomas induced by $\mathrm{N}$-nitrosobis (2-oxopropyl) amine in female Syrian golden hamsters [11]. FHIT-deficient mice easily developed forestomach tumors and invasive bladder carcinoma after the treatment with $\mathrm{N}$-nitrosomethylbenzylamine and N-butyl-N- (4-hydroxybutyl) nitrosamine respectively [12, 13]. BBN(N-butyl-N-(-4-hydroxybutyl)- nitrosamine)induced urinary bladder cancer could be prevented in FHIT knock-out mouse by Rofecoxib, a cox-2 inhibitor [14]. Lung cancer susceptibility in FHIT-deficient mice was increased by Vhl haploinsufficiency [15]. Fujishita et al. [16] found that FHIT knockout mice developed tumors in the lymphoid tissue, liver, uterus, testis, forestomach and small intestine. In the present study, we performed a meta- and bioinformatics analysis to clarify the clinicopathological and prognostic significances of FHIT expression in gastric cancer at both mRNA and protein levels.

\section{RESULTS}

\section{Characteristics of eligible studies}

Figure 1 is a flow diagram of article selection for our meta-analysis. As shown in Table 1, a total of 21 articles on the relationship between FHIT expression and cancer risk, clinicopathological or prognostic parameters of gastric cancer were retrieved for our meta-analysis by immunohistochemistry from PubMed, Web of Science, BIOSIS, SciFinder and CNKI. Only 10 articles contained the samples of normal gastric mucosa [17-26] and 7 did gastric precancerous lesion-dysplasia [17, 22, 25-29]. There appeared the comparison between FHIT expression and clinicopathological characteristics of gastric cancer in 19 pieces of paper, including sex, depth of invasion, lymph node metastasis, distant metastasis, TNM staging and Lauren's classification [17-36]. Finally, we discussed the prognostic significance of FHIT expression in 7 articles $[20,25,30-32,36,37]$.

\section{Association between FHIT expression and cancer susceptibility of gastric mucosa or dysplasia}

We analyzed the association between FHIT expression and cancer susceptibility of gastric normal mucosa in 10 studies with 1113 cancers and 518 controls. As a result, we found down-regulated FHIT expression in gastric cancer, compared with normal mucosa (Figure $2 \mathrm{~A}, p<0.00001)$. Additionally, the cancer risk of FHITnegative dysplasia was also analyzed and the same trend was observed as gastric mucosa using 656 cancer and 228 dysplasia (Figure 2B, $p=0.0003$ ).

\section{Association between FHIT expression and clinicopathological parameters of gastric cancer}

There was no difference in FHIT expression between male and female patients with gastric cancer (Figure $2 \mathrm{C}, p>0.05$ ) or between younger and elder cancer patients (Figure 2D, $p>0.05$ ). A higher FHIT expression was detected in T0-1 than T2-4 gastric cancer (Figure $2 \mathrm{E}, p<0.00001$ ) or T0-2 than T3-4 ones (Figure 2F, $p=$ $0.009)$. FHIT expression was negatively related to lymph node metastasis (Figure $2 \mathrm{G}, p<0.00001$ ) and distant metastasis (Figure 2H, $p=0.0002$ ) of gastric cancer. Stage $0-$ I and $0-$ II cancers showed higher FHIT expression than stage II-IV (Figure 2I, $p=0.0009$ ) and III-IV (Figure 2J, p $<0.00001)$ respectively. FHIT protein was more expressed in intestinal-type than diffuse-type carcinomas (Figure $2 \mathrm{~K}$, $p<0.00001)$.

\section{Association between FHIT expression and survival rate of gastric cancer}

As indicated in Figure 2L, the pooled result from 7 datasets demonstrated a positive association between FHIT expression and favorable overall survival in the patients with gastric cancer $(\mathrm{HR}=1.53,95 \% \mathrm{CI}: 1.30$ $1.80, p<0.0001)$.

\section{Publication bias}

The heterogeneity test was performed as shown in Figure 3. Sensitivity analysis was used to evaluate individual study's influence on the pooled results by deleting one single study each time from pooled analysis. As a result, the correlation between FHIT expression and TNM staging in Wang's study had a significant effect on the pooled OR as shown in Figure 2I. When this study was excluded, the heterogeneity test was significantly reduced (data not shown).

\section{The clinicopathological and prognostic significances of FHIT mRNA expression in gastric cancers}

According to Oncomine dataset, there was no difference in FHIT mRNA expression between gastric mucosa and cancer ( $p>0.05$, data not shown). In TCGA data, FHIT mRNA expression was not correlated with any clinicopathological parameter of gastric cancer $(p>0.05$, data not shown). According to Kaplan-Meier plotter, we found that a higher FHIT mRNA expression was negatively correlated with overall and progression-free survival rates of all cancer patients, even stratified by gender and Her2 status (Figure 4 and Table 2, $p<0.05$ ). It was the same for the N1-3, N1, stage II and III, diffuse-type cancer patients (Table 2, $p<0.05$ ). M0 and intestinal-type cancer patients with high FHIT mRNA expression showed a short overall survival time than those with its low expression (Table 2, $p<$ 
Table 1: Main characteristics of eligible studies

\begin{tabular}{|c|c|c|c|c|c|c|c|c|c|}
\hline First author & Year & Country & Ethnicity & $\begin{array}{l}\text { Antibody } \\
\text { Source }\end{array}$ & Cases & Control & $\begin{array}{l}\text { Risk to } \\
\text { cancer }\end{array}$ & Outcome & Quality \\
\hline Bria E & 2013 & Italy & European & Neomarker & 208 & - & - & Positive & 8 \\
\hline Zheng HC & 2010 & Japan & Asian & Neomarker & 377 & - & - & - & 8 \\
\hline Czyzewska J & 2009 & Poland & European & Abcam & 80 & - & - & - & 8 \\
\hline Zheng HC & 2008 & Japan & Asian & Neomarker & 270 & - & - & - & 8 \\
\hline Zheng HC & 2007 & Japan & Asian & Neomarker & 242 & 49 & Down & Positive & 9 \\
\hline Hara A & 2007 & Japan & Asian & IBL & 103 & - & - & - & 8 \\
\hline Bragantini E & 2006 & Italy & European & Zymed & 362 & - & - & Positive & 8 \\
\hline Zhao P & 2005 & China & Asian & Zymed & 76 & 76 & Down & Positive & 9 \\
\hline Kawaguchi K & 2004 & Japan & Asian & IBL & 55 & - & - & - & 8 \\
\hline Skopelitou AS & 2003 & Greece & European & Zymed & 59 & - & - & - & 8 \\
\hline Lee HS & 2003 & Korea & Asian & Zymed & 329 & - & - & Positive & 8 \\
\hline Rocco A & 2003 & Germany & European & Zymed & 137 & - & - & - & 8 \\
\hline Capuzzi D & 2000 & USA & American & Self-making & 55 & - & - & Positive & 8 \\
\hline Yang Y & 2016 & China & Asian & Zhongshan & 86 & 33 & Down & - & 9 \\
\hline Chang TM & 2013 & China & Asian & Zhongshan & 30 & 60 & Down & - & 8 \\
\hline Ma YY & 2011 & China & Asian & Zhongshan & 70 & 30 & Down & - & 8 \\
\hline Li DX & 2009 & China & Asian & Zhongshan & 50 & 30 & Down & - & 8 \\
\hline Zhu SZ & 2009 & China & Asian & Zhongshan & 52 & 48 & Down & - & 8 \\
\hline Li YZ & 2009 & China & Asian & Zymed & 336 & 60 & Down & Positive & 9 \\
\hline Guo XQ & 2006 & China & Asian & Santa Cruz & 80 & 80 & Down & - & 8 \\
\hline Wang $\mathrm{P}$ & 2002 & China & Asian & Zhongshan & 78 & - & Down & - & 8 \\
\hline
\end{tabular}

Down, down-regulated expression.

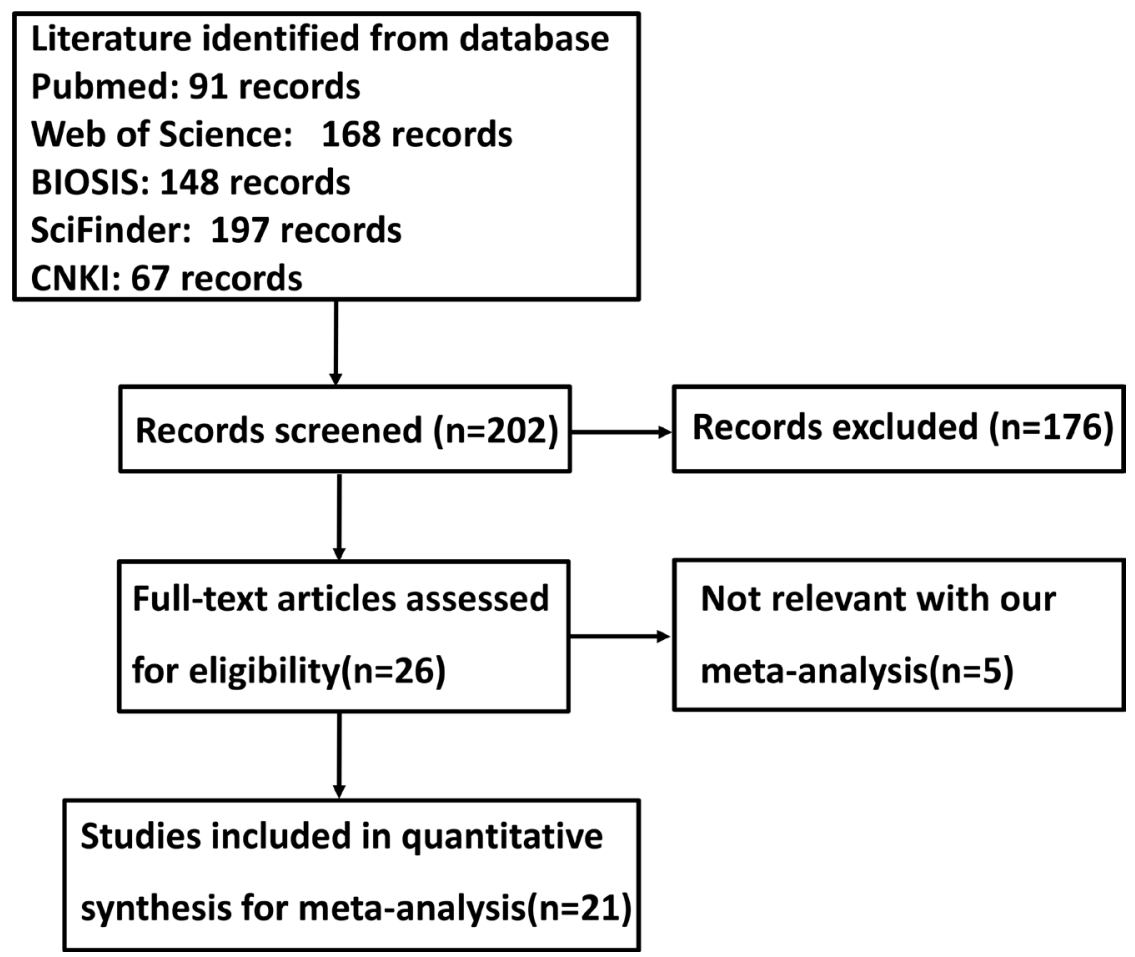

Figure 1: Flow diagram of the selection process in this meta-analysis. 


\begin{tabular}{|c|c|c|c|c|}
\hline \multirow{2}{*}{ Clinicopathological features } & \multicolumn{2}{|c|}{ Overall survival } & \multicolumn{2}{|c|}{ Progression-free survival } \\
\hline & Hazard ratio & $p$ & Hazard ratio & $p$ \\
\hline \multicolumn{5}{|l|}{ Sex } \\
\hline Female & $1.7(1.17-2.45)$ & 0.0044 & $1.62(1.1-2.38)$ & 0.013 \\
\hline Male & $1.61(1.3-2.01)$ & $1.7 \mathrm{e}^{-05}$ & $1.52(1.17-1.96)$ & 0.0016 \\
\hline \multicolumn{5}{|l|}{$\mathrm{T}$} \\
\hline 2 & $1.3(0.83-2.01)$ & 0.25 & $1.19(0.76-1.85)$ & 0.44 \\
\hline 3 & $1.33(0.94-1.89)$ & 0.11 & $1.17(0.82-1.66)$ & 0.39 \\
\hline 4 & $3.38(1.29-8.88)$ & 0.0096 & $5.09(1.65-15.65)$ & 0.0021 \\
\hline \multicolumn{5}{|l|}{$\mathrm{N}$} \\
\hline 0 & $1.76(0.75-4.17)$ & 0.19 & $1.69(0.71-3.98)$ & 0.23 \\
\hline $1-3$ & $1.46(1.1-1.94)$ & 0.0079 & $1.37(1.04-1.8)$ & 0.024 \\
\hline 1 & $2.17(1.37-3.44)$ & $7 e-04$ & $1.79(1.21-2.65)$ & 0.0032 \\
\hline 2 & $1.55(0.92-2.64)$ & 0.099 & $1.39(0.87-2.2)$ & 0.17 \\
\hline 3 & $0.73(0.41-1.28)$ & 0.27 & $0.67(0.38-1.17)$ & 0.15 \\
\hline \multicolumn{5}{|l|}{ M } \\
\hline 0 & $1.43(1.08-1.91)$ & 0.013 & $1.26(0.97-1.65)$ & 0.083 \\
\hline 1 & $1.69(0.89-3.21)$ & 0.11 & $1.38(0.71-2.67)$ & 0.34 \\
\hline \multicolumn{5}{|l|}{ TNM staging } \\
\hline I & $2.81(0.96-8.26)$ & 0.051 & $1.98(0.62-6.28)$ & 0.24 \\
\hline II & $1.94(1.06-3.53)$ & 0.028 & $0.5(0.24-1.01)$ & 0.049 \\
\hline III & $1.81(1.35-2.43)$ & $5.3 e-05$ & $1.84(1.24-2.72)$ & 0.0021 \\
\hline IV & $0.71(0.46-1.08)$ & 0.11 & $0.64(0.42-0.97)$ & 0.034 \\
\hline \multicolumn{5}{|l|}{ Lauren's classification } \\
\hline Intestinal-type & $1.74(1.27-2.39)$ & 0.00053 & $0.81(0.55-1.2)$ & 0.3 \\
\hline Diffuse-type & $1.65(1.17-2.33)$ & 0.0038 & $1.52(1.07-2.14)$ & 0.017 \\
\hline Mixed-type & $2.41(0.87-6.68)$ & 0.082 & $1.71(0.55-5.39)$ & 0.35 \\
\hline \multicolumn{5}{|l|}{ Her2 positivity } \\
\hline- & $1.62(1.29-2.02)$ & $2.5 e^{-05}$ & $1.42(1.08-1.87)$ & 0.01 \\
\hline+ & $1.37(1.03-1.83)$ & 0.031 & $1.47(1.05-2.05)$ & 0.023 \\
\hline \multicolumn{5}{|l|}{ Treatment } \\
\hline Surgery alone & $1.27(0.94-1.7)$ & 0.11 & $1.15(0.85-1.56)$ & 0.37 \\
\hline 5-FU-based adjuvant & $0.73(0.51-1.03)$ & 0.071 & $0.7(0.5-0.99)$ & 0.044 \\
\hline Other adjuvant & $0.44(0.17-1.1)$ & 0.07 & $0.48(0.22-1.07)$ & 0.068 \\
\hline
\end{tabular}

0.05). There appeared a negative relationship between FHIT mRNA expression and the progression-free survival rate of T4 cancer patients (Table 2, $p<0.05$ ).

\section{DISCUSSION}

FHIT can interact with Gaq to enhance the growth inhibitory effect of FHIT [38], and with ubiquitinconjugating enzyme 9 to inhibit its diadenosine triphosphate hydrolase activity [39, 40]. FHIT induces autophagy and apoptosis in lung cancer cells, and suppresses the growth epithelial-mesenchymal transition (EMT) and metastasis [41-43]. Further investigation showed that FHIT inhibited EMT through an EGFR/Src/ ERK/Slug signaling axis in human bronchial cells [44]. Huang et al. [45] found that FHIT suppressed proliferation and promoted apoptosis in cholangiocarcinoma cells by blocking PI3K-Akt pathway. Nakagawa et al. [46] demonstrated that FHIT overexpression suppressed colorectal cell viability, and resulted in a higher sensitivity 
A

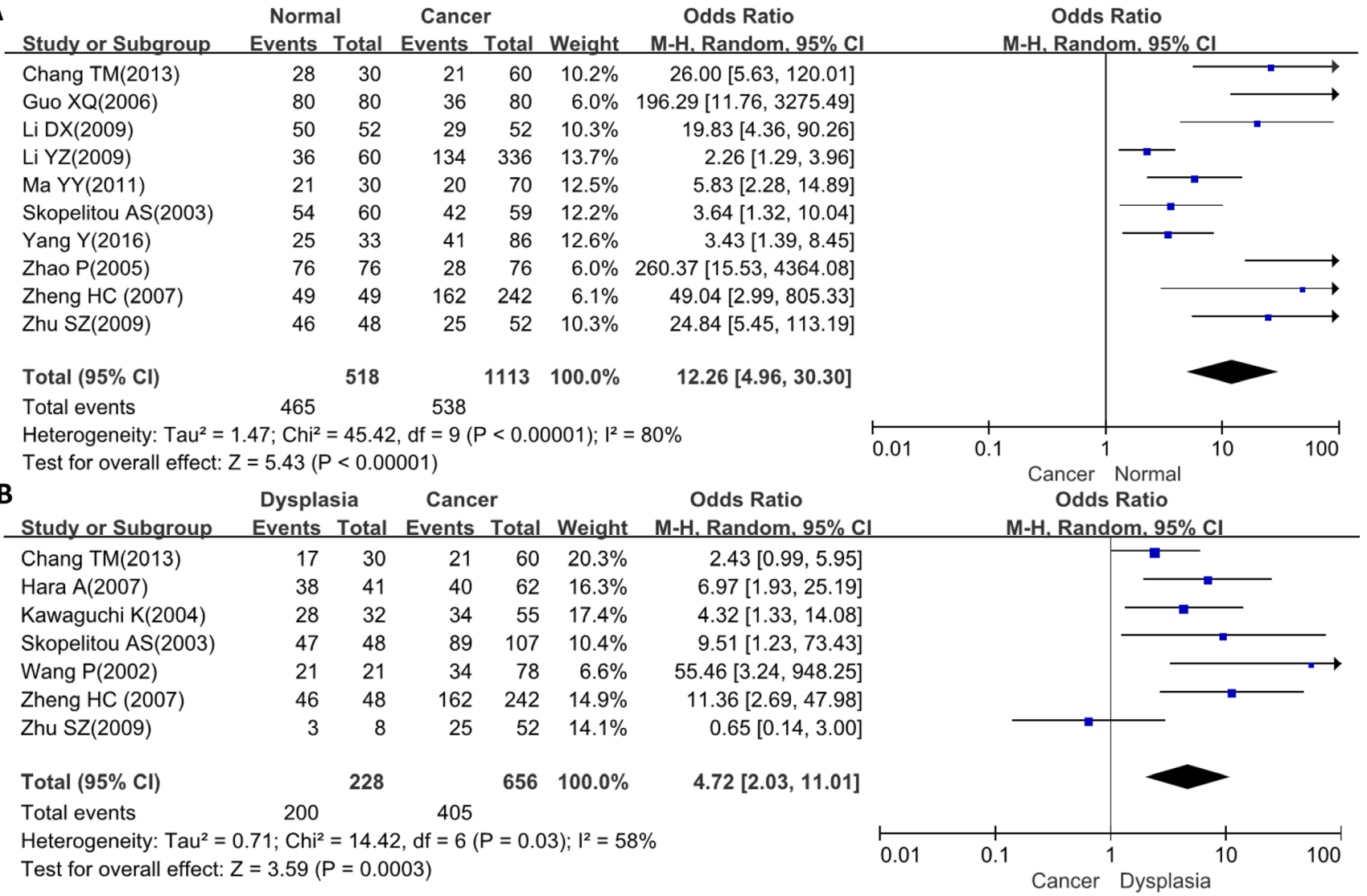

C

Male Female Odds Ratio Odds Ratio

Study or Subgroup Events Total Events Total Weight M-H. Fixed. 95\% C

$0.97[0.60,1.58]$

Bragantini $E(2006)$

$\begin{array}{lllll}64 & 228 & 35 & 122 & 36.4 \%\end{array}$

$\begin{array}{llllll}\text { Czyzewska J (2009) } & 27 & 54 & 18 & 26 & 13.5 \%\end{array}$

Li DX(2009)

Ma YY(2011)

Yang $Y(2016)$

Zheng $\mathrm{HC}(2007)$

Zhu SZ(2009)

$21 \quad 39$

$8 \quad 13 \quad 6.1 \%$

$0.44[0.17,1.19]$

$0.73[0.20,2.63]$

$0.82[0.26,2.58]$

$0.78[0.28,2.15]$

$1.34[0.74,2.42]$

$0.89[0.28,2.79]$

Total $(95 \% \mathrm{Cl})$

651

$\begin{array}{lll}6 & 19 & 7.0 \%\end{array}$

$\begin{array}{lllll}32 & 69 & 10 & 19 & 9.3 \%\end{array}$

$121 \quad 176$

$41 \quad 66 \quad 20.7 \%$

Total events $295 \quad 127$

$283100.0 \%$

Heterogeneity: $\mathrm{Chi}^{2}=3.96, \mathrm{df}=6(\mathrm{P}=0.68) ; \mathrm{I}^{2}=0 \%$

Test for overall effect: $Z=0.50(P=0.62)$

$$
<60 \text { years } \geqq 60 \text { years }
$$

$0.93[0.69,1.25]$

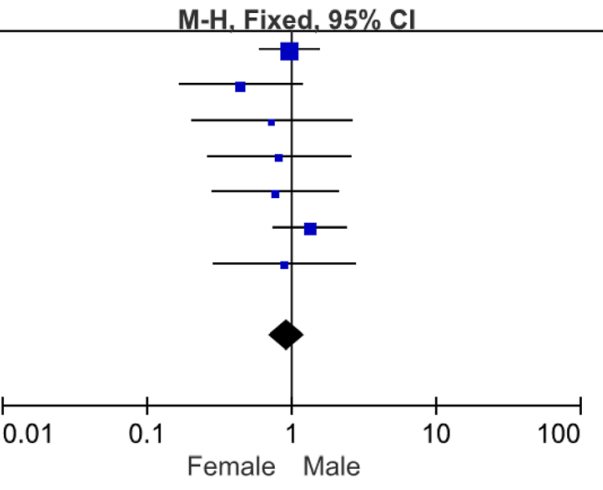

Odds Ratio

D

\begin{tabular}{|c|c|c|c|c|c|}
\hline Study or Subgroup & Events & otal & Events & Tota & \\
\hline Czyzewska J (2009) & 14 & 29 & 31 & 51 & 17.2 \\
\hline Li DX(2009) & 12 & 23 & 17 & 29 & $10.7^{\circ}$ \\
\hline Ma YY(2011) & 8 & 25 & 12 & 45 & 8.6 \\
\hline Yang $Y(2016)$ & 9 & 30 & 33 & 56 & 23.9 \\
\hline Zheng HC (2007) & 37 & 55 & 125 & 187 & 27.6 \\
\hline Zhu SZ(2009) & 11 & 26 & 14 & 26 & 12. \\
\hline Total $(95 \% \mathrm{Cl})$ & \multicolumn{3}{|c|}{188} & 394 & \multirow[t]{2}{*}{$100.0 \%$} \\
\hline Total events & 91 & & 232 & & \\
\hline $\begin{array}{l}\text { Heterogeneity: } \text { Chi }^{2} \\
\text { Test for overall effec }\end{array}$ & $\begin{array}{l}3, \mathrm{df}= \\
=1.73(\end{array}$ & & 1. $1^{2}$ & & \\
\hline
\end{tabular}

M-H. Fixed. $95 \% \mathrm{Cl}$

$0.60[0.24,1.51]$

$0.77[0.26,2.32]$

$1.29[0.44,3.77]$

$0.30[0.12,0.77]$

$1.02[0.54,1.93]$

$0.63[0.21,1.88]$

$0.73[0.50,1.04]$

Odds Ratio

M-H, Fixed, $95 \% \mathrm{Cl}$

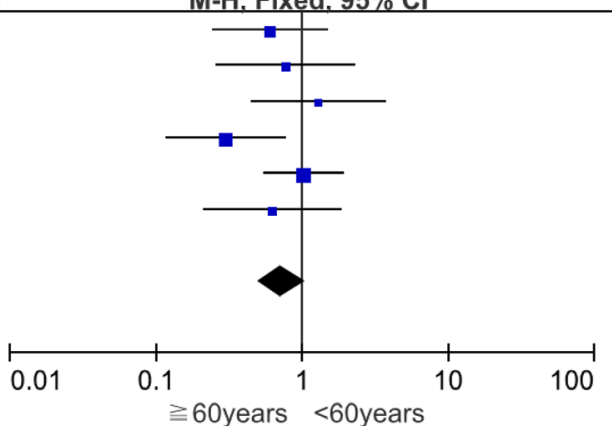


T0-1

T2-4

Odds Ratio

Odds Ratio

E Study or Subgroup Events Total Events Total Weight M-H, Fixed, $95 \% \mathrm{Cl}$ Capuzzi D(2000) Czyzewska J (2009) Li DX(2009) Li YZ(2009) Wang $\mathrm{P}(2002)$ Zheng HC (2007) Zhu SZ(2009)

$\begin{array}{llllll}4 & 4 & 24 & 51 & 1.4 \% & 10.10[0.52,197.31]\end{array}$

$\begin{array}{llllll}6 & 11 & 39 & 69 & 16.0 \% & 0.92[0.26,3.32]\end{array}$

$\begin{array}{llllll}9 & 11 & 20 & 41 & 5.1 \% & 4.72[0.91,24.60]\end{array}$

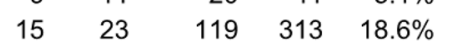

$\begin{array}{lllll}0 & 1 & 34 & 77 & 4.3 \%\end{array}$

$\begin{array}{lllll}92 & 120 & 70 & 122 & 53.2 \%\end{array}$

Total $(95 \% \mathrm{CI})$

172

$723 \quad 100.0 \%$

Total events

128 329

Heterogeneity: $\mathrm{Chi}^{2}=5.42, \mathrm{df}=6(\mathrm{P}=0.49) ; \mathrm{l}^{2}=0 \%$

Test for overall effect: $Z=4.42(P<0.00001)$

$\mathbf{F}$

T0-2

T3-4

Study or Subgroup Events Total Events Total Weight $\mathrm{M}-\mathrm{H}, \mathrm{Fixed}, 95 \% \mathrm{CI}$

Capuzzi D(2000)

Czyzewska J (2009)

Guo XQ(2006)

Li YZ(2009)

Ma YY(2011)

Rocco A(2003)

Wang $P(2002)$

Zhu SZ(2009)

$\begin{array}{rrrrr}9 & 17 & 19 & 38 & 8.5 \% \\ 14 & 27 & 31 & 53 & 15.6 \% \\ 18 & 43 & 18 & 37 & 17.4 \% \\ 62 & 128 & 72 & 210 & 43.5 \% \\ 10 & 19 & 10 & 51 & 4.0 \% \\ 6 & 6 & 72 & 101 & 1.0 \% \\ 29 & 68 & 5 & 10 & 7.7 \% \\ 6 & 8 & 19 & 44 & 2.3 \%\end{array}$

Total $(95 \% \mathrm{CI})$

$154 \quad 316$

Total events

$544100.0 \%$

Heterogeneity: $\mathrm{Chi}^{2}=11.87, \mathrm{df}=7(\mathrm{P}=0.11) ; \mathrm{I}^{2}=41 \%$

Test for overall effect: $Z=2.61(P=0.009)$
$3.06[1.26,7.43]$

$0.42[0.02,10.64]$

$2.44[1.40,4.25]$

$5.85[0.27,128.06]$

$2.50[1.67,3.75]$

M-H, Fixed, 95\% Cl

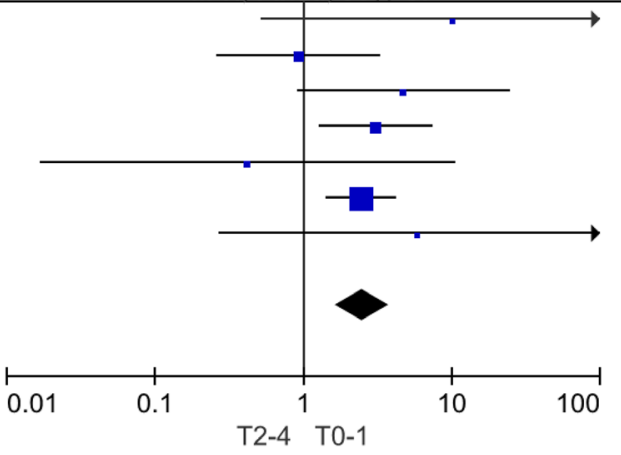

Odds Ratio

M-H, Fixed, $95 \% \mathrm{Cl}$

$1.13[0.36,3.54]$

$0.76[0.30,1.94]$

$0.76[0.31,1.84]$

$1.80[1.15,2.82]$

$4.56[1.46,14.18]$

$5.29[0.29,96.92]$

$0.74[0.20,2.81]$

$3.95[0.72,21.78]$

$1.51[1.11,2.06]$

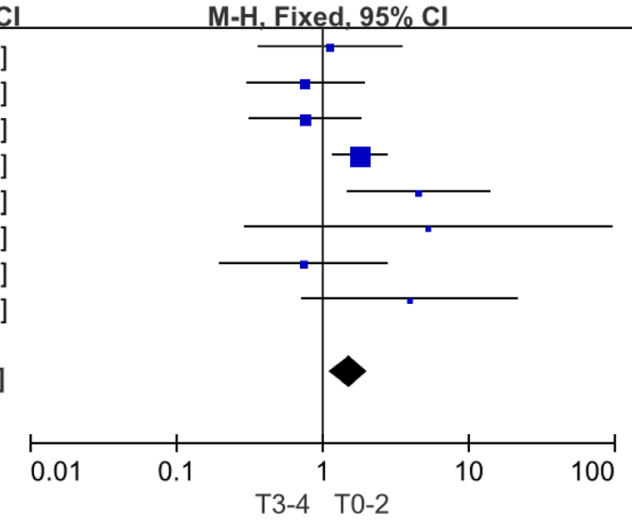

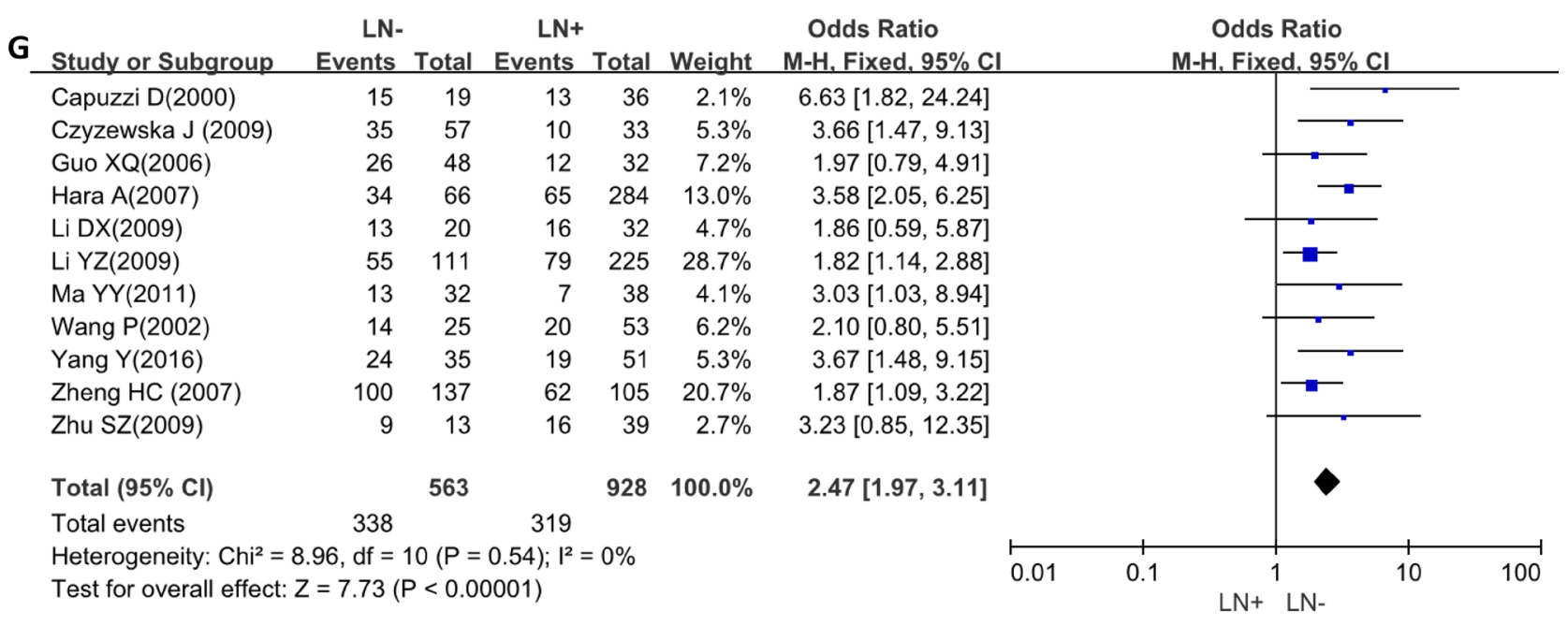

DM- $\quad \mathrm{DM}+$

Odds Ratio

Odds Ratio

H Study or Subgroup Events Total Events Total Weight M-H, Fixed, $95 \% \mathrm{Cl}$

Bragantini $\mathrm{E}(2006)$

Zhao P(2005)

Zheng HC (2007)

$\begin{array}{rrrrr}93 & 306 & 6 & 44 & 32.1 \% \\ 129 & 320 & 12 & 46 & 55.1 \% \\ 157 & 227 & 5 & 15 & 12.7 \%\end{array}$

$2.77[1.13,6.77]$

$1.91[0.96,3.83]$

$4.49[1.48,13.61]$

Total $(95 \% \mathrm{CI})$

853

$105 \quad 100.0 \%$

$2.51[1.54,4.12]$

Total events

379 23

Heterogeneity: $\mathrm{Chi}^{2}=1.68, \mathrm{df}=2(\mathrm{P}=0.43) ; \mathrm{I}^{2}=0 \%$

Test for overall effect: $Z=3.66(P=0.0002)$

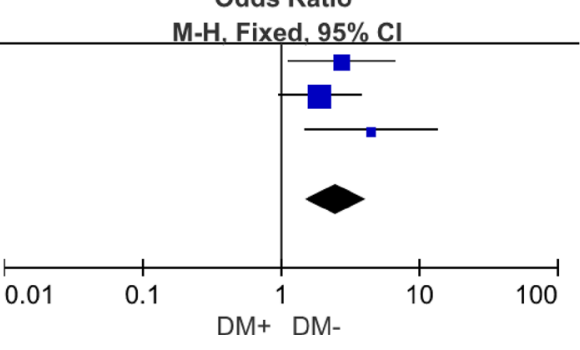




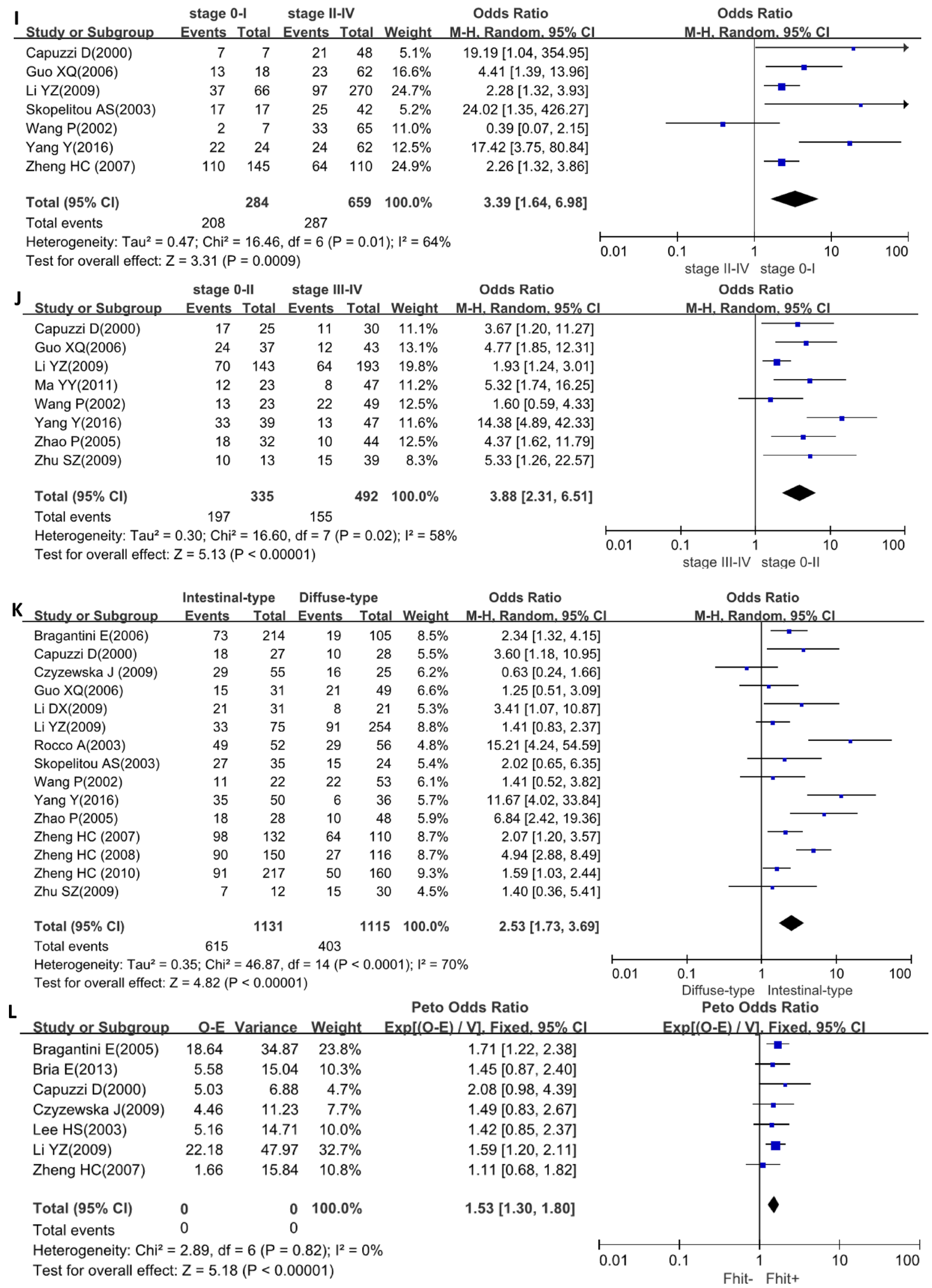

Figure 2: Forest plot for the relationship between FHIT expression and clinicopathological parameters of gastric cancer. (A), Gastric carcinogenesis (cancer vs normal mucosa); (B), gastric carcinogenesis (cancer vs dysplasia); (C), correlation between sex and FHIT expression (male vs female); (D), correlation between age and FHIT expression (<60years vs $\geqq 60$ years); (E), correlation between depth of invasion and FHIT expression (T0-1 vs T2-4); (F), correlation between depth of invasion and FHIT expression (T0-2 
vs T3-4); (G), correlation between lymph node metastasis (LN) and FHIT expression (LN- vs LN+); (H), correlation between distant metastasis (DM) and FHIT expression (DM- vs DM+); (I), correlation between TNM staging and FHIT expression (stage 0-I vs II-IV); (J), correlation between TNM staging and FHIT expression (stage 0-II vs III-IV); (K), correlation between differentiation and FHIT (intestinaltype vs diffuse-type); (L), correlation between survival and FHIT expression (FHIT- vs FHIT + ).

to oxidative stress evoked by inhibitors of mitochondrial electron transport. Vecchione et al. [13] found FHIT overexpression inhibited cell growth, increased apoptotic cell population, and suppressed tumor growth in nude mice of the bladder cancer cells. To investigate the clinicopathological and prognostic significances of FHIT expression, we analyzed 21 studies, which met specific inclusion criteria and had moderate to high quality according to their NOS scores.

Consistent with the data about colorectal cancer [47], bladder cancer [48], thyroid cancer [49] and lung cancer [50], we found down-regulated FHIT expression in gastric cancer, compared with gastric mucosa or dysplasia in the present study, suggesting that FHIT hypoexpression contributes to gastric carcinogenesis as a late event. Huang et al. [51] found that cervical microinvasive and invasive carcinomas had significantly lower FHIT expression than normal epithelium and dysplasia. Kuwai et al. [52] demonstrated that FHIT protein expression were lower in invasive colorectal carcinoma than in adenoma and carcinoma in situ. Combined with these findings, it was suggested that gradual FHIT down-regulation promoted gastric carcinogenesis.
Reportedly, FHIT down-regulation or loss might be due to its promoter methylation and loss of heterozygosity in cancers, but not its gene mutation [47, 49, 53, 54].

Here, our meta-analysis showed FHIT expression was inversely linked to depth of invasion, lymph node metastasis, distant metastasis and TNM staging of gastric cancer, indicating that its hypoexpression promoted invasion and metastasis of gastric cancer, in agreement with the reports about oral squamous cell carcinoma [55], cholangiocarcinoma [56], colorectal cancer [57], and cervical cancer [58]. FHIT promoter hypermethylation was positively linked to tumor staging, pathological grade, or lymph node metastasis of colorectal cancer [59], thyroid cancer [49] and lung cancer [60]. Chen et al. [61] found that FHIT mRNA expression had an inverse relation with larger invasive range, poor histological differentiation and advanced clinical stage of nasopharyngeal carcinoma. Yin et al. [54] reported that homozygous deletion of exon 5 of FHIT was positively associated with lymph node metastasis of differentiated thyroid cancer and the homozygous deletion of exon 8 was positively associated
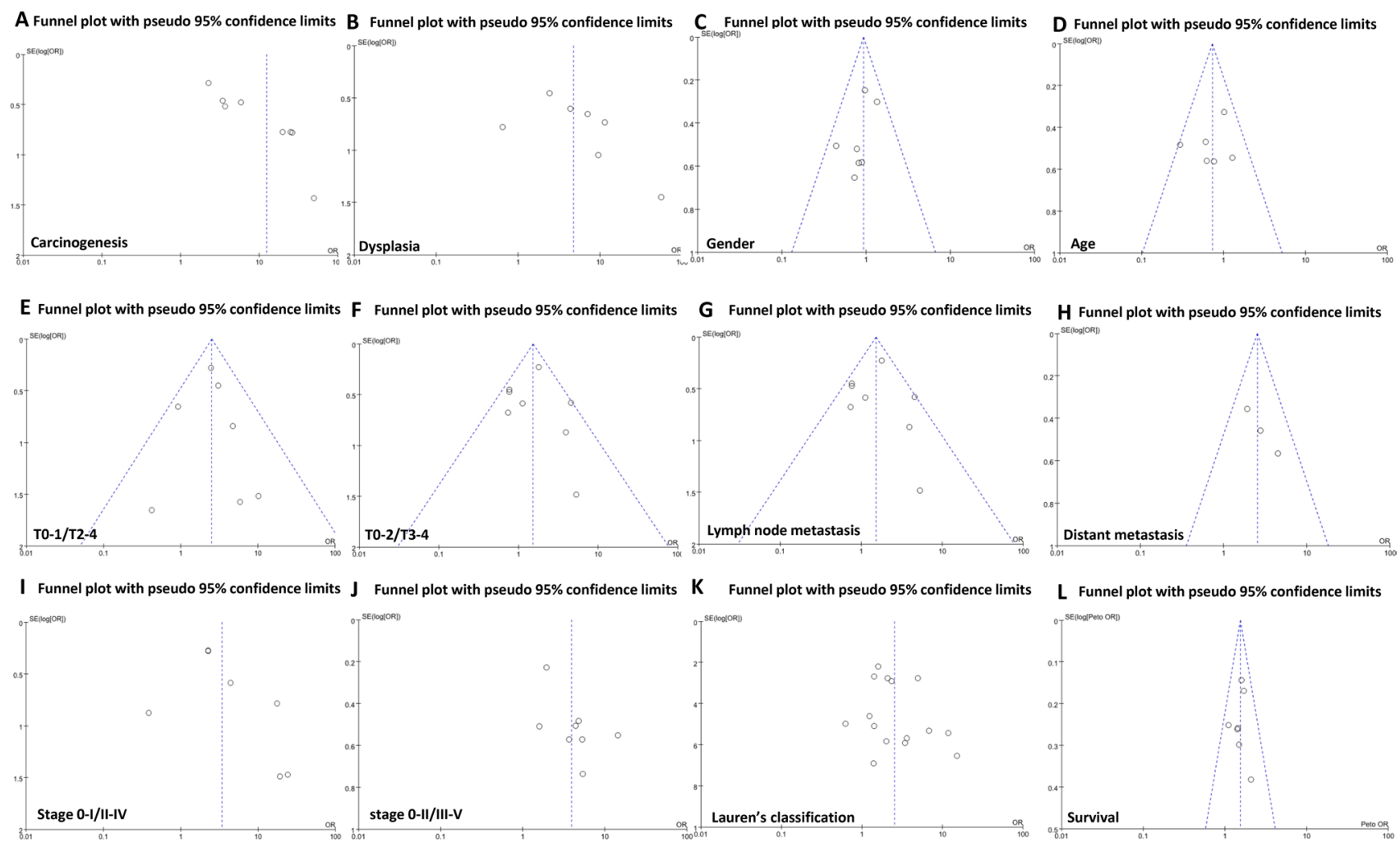

Figure 3: Funnel plot for publication bias test between FHIT expression and gastric carcinogenesis or progression. The bias was analyzed about risk degrees of FHIT expression in gastric mucosa (A) and dysplasia (B) for gastric carcinogenesis. Additionally, it was tested between FHIT expression and clinicopathological features of gastric cancer, including gender (C), age (D), depth of invasion $(\mathbf{E}$ and $\mathbf{F})$, lymph node metastasis $(\mathbf{G})$, distant metastasis $(\mathbf{H})$, TNM staging (I and $\mathbf{J})$, differentiation (K) and prognosis $(\mathbf{L})$. 
with the tumor pathological grade, TNM staging, and lymph node metastasis of differentiated thyroid cancer. Taken together, we concluded that FHIT loss might be employed as a potential biomarker for aggressiveness of gastric cancer.

Reportedly, FHIT expression was positively related to the favorable prognosis of the patients with lung cancer [62], oral squamous cell carcinoma [55], head and neck squamous cell carcinoma [63], diffuse large B-cell lymphoma [64] and cervical cancer [51]. It might be also demonstrated to indicate the favorable prognosis of cholangiocarcinoma [58], non-small cell lung cancer [65], cervical cancer [66], renal clear cell carcinoma [67] and tongue cancer [68] as an independent factor. Our meta-analysis showed that FHIT expression was positively linked to the favorable prognosis of the patients with gastric cancer. In contrast, our bioinformatics data indicated that FHIT mRNA expression was negatively associated with overall and progression-free survival rates of the patient with gastric cancer, even stratified by clinicopathological features. The paradoxical results are not strange since mRNA levels do not usually predict the corresponding protein levels because it takes a long distance from mRNA to functional protein by translation and posttranslational modification.

In conclusion, FHIT expression underwent a downregulation during gastric carcinogenesis as a late event. It was negatively correlated with depth of invasion, lymph node metastasis, distant metastasis, TNM staging and dedifferentiation of gastric cancer. FHIT expression might be employed as a good potential marker for favorable prognosis of gastric cancer patients, while it was the converse for its mRNA. The limitations of this study include the potential publication bias from positive results in articles and the survival data extraction from survival curves.

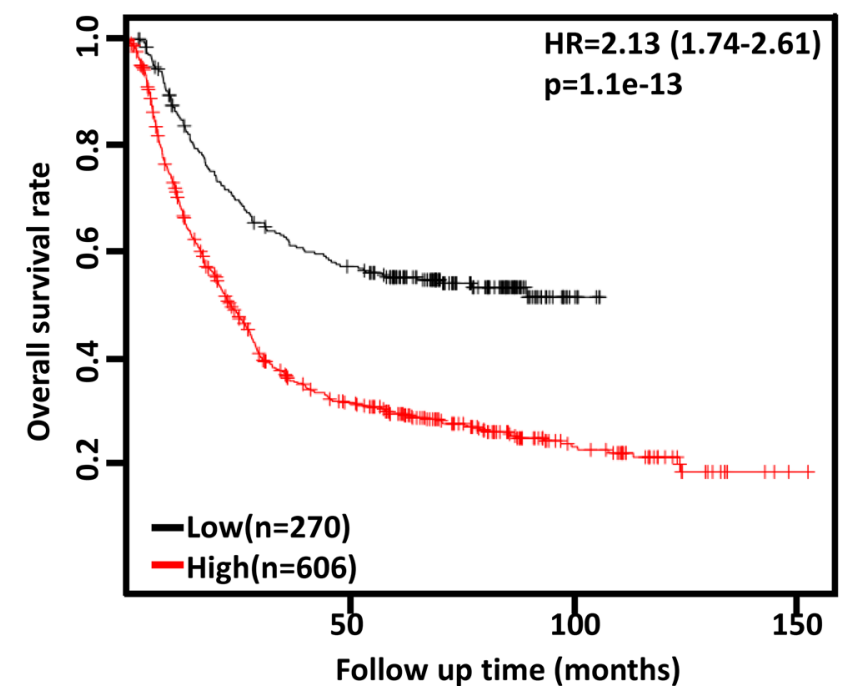

\section{MATERIALS AND METHODS}

\section{Identification of eligible studies and data extraction}

We performed a publication search using PubMed, Web of Science, BIOSIS, SciFinder and CNKI updated on March 14, 2017. The following search terms were used: (FHIT OR fragile histine triad) AND (gastric OR stomach) AND (cancer OR carcinoma OR adenocarcinoma). Searching was done without restriction on language or publication years. Inclusion criteria for studies: (1) articles to observe the alteration in FHIT expression in gastric cancer by immunohistochemistry; (2) papers to compare FHIT expression with pathobiological behaviors and prognosis of gastric cancer by immunohistochemistry. Exclusion criteria included: (1) abstract, comment, review and meeting; (2) duplication of the previous publications; (3) Western blot, RT-PCR, cDNA microarray, or transcriptomic sequencing for FHIT expression; (4) lack of sufficient information.

\section{Data extraction}

Based on the inclusion criteria, two reviewers (HC Zheng and LL Liu) independently extracted information from all eligible publications. The following information were included in each study: name of first author, year of publication, country, ethnicity, cancer types, source of control, antibody company, numbers of cases and controls, expression alteration, correlation with aggressive features, and follow-up times. Regarding survival analysis, we used Engauge Digitizer software to extract data from KaplanMeier curves and calculated the Hazard ratios (HR) and their corresponding 95\% confidence intervals (CI). Any disagreement was resolved through discussion until the two reviewers reached a consensus.

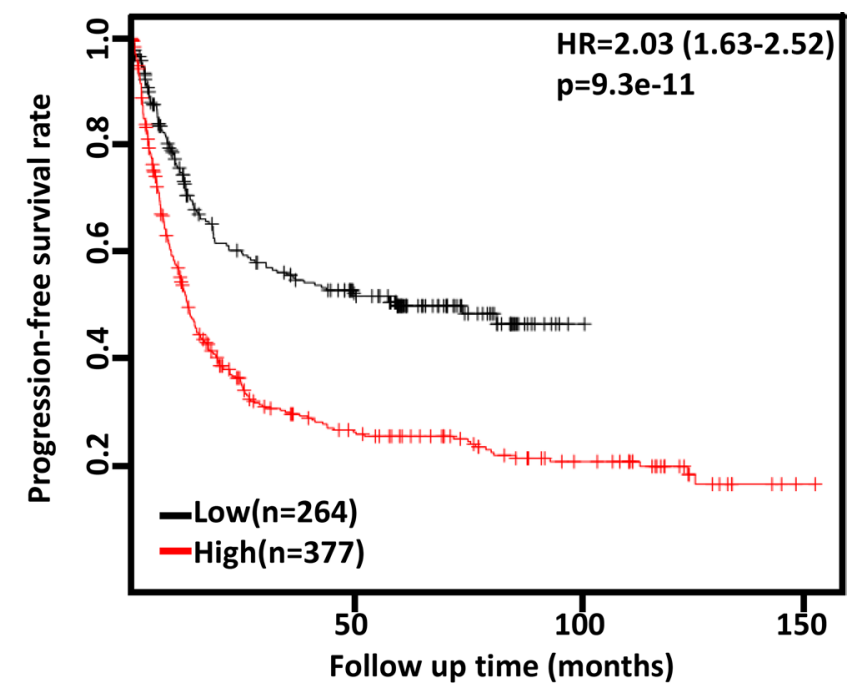

Figure 4: The prognostic significance of FHIT mRNA expression in gastric cancer. According to the data from Kaplan-Meier plotter, FHIT mRNA expression was negatively related to both overall and progression-free survival rates of the patients with gastric cancer $(p<0.05)$. HR, hazard ratio. 


\section{Quality score assessment}

Two reviewers (HC Zheng and LL Liu) independently assessed the quality of the included studies according to Newcastle Ottawa Scale (NOS) (http://www. ohri.ca/programs/clinical_epidemiology/oxford.htm).

The scale consists of three components related to sample selection, comparability and ascertainment of outcome.

\section{Bioinformatics analysis}

The individual gene expression level of FHIT was analyzed using Oncomine (www. oncomine.org), a cancer microarray database and web-based data mining platform for a new discovery from genomewide expression analyses. We compared the differences in FHIT mRNA level between gastric normal tissue and cancer. All data were log-transformed, median centered per array, and standard deviation normalized to one per array. The expression data (RNA-seqV2) and clinicopathological data of 392 gastric cancer patients were downloaded from the Cancer Genome Atlas (TCGA) database by TCGA-assembler in R software. We integrated the raw data, analyzed FHIT expression in gastric cancer, and compared it with clinicopathological and prognostic data of the patients with gastric cancer. Additionally, the prognostic significance of FHIT mRNA was also analyzed using Kaplan-Meier plotter (http:// kmplot.com).

\section{Statistics analysis}

HWE was evaluated using Chi-square test in control groups of each study. Strength of association between FHIT expression and cancer risk was assessed by odds ratios with $95 \%$ confidence intervals. Statistical significance of the pooled OR was determined by $Z$ test. If there was no significant heterogeneity, the fixed effect model (Mantel-Haenszel method) would be employed. Otherwise, the random effect model (DerSimonian and Laird method) would be used excluding prognostic analysis. Heterogeneity effect was then quantified by $\mathrm{I}^{2}$ test, which was subdivided into low, moderate and high degrees of heterogeneity according to the cut-off values of $25 \%, 50 \%$ and $75 \%$ respectively. Publication bias was evaluated by funnel plot and quantified by Begg's test and Egger's test to assess funnel plot asymmetry. Metaanalyses were performed with Revman software 5.3 and data from TCGA database was dealt with SPSS 10.0 software using student $t$ test. Two-sided $p<0.05$ was considered as statistically significant.

\section{CONFLICTS OF INTEREST}

The authors have declared that no competing interests exist.

\section{FUNDING}

This study was supported by Liaoning BaiQianWan Talents Program, Outstanding Scientific Fund of Shengjing Hospital, Award for Liaoning Distinguished Professor, a Key Scientific and Technological Project of Liaoning Province (2015408001) and National Natural Scientific Foundation of China (81472544; 81672700).

\section{REFERENCES}

1. Waters CE, Saldivar JC, Hosseini SA, Huebner K. The FHIT gene product: tumor suppressor and genome “caretaker”. Cell Mol Life Sci. 2014; 71:4577-4587.

2. Karras JR, Schrock MS, Batar B, Zhang J, La Perle K, Druck T, Huebner K. Fhit loss-associated initiation and progression of neoplasia in vitro. Cancer Sci. 2016; 107:1590-1598.

3. Bianchi F, Magnifico A, Olgiati C, Zanesi N, Pekarsky Y, Tagliabue E, Croce CM, Ménard S, Campiglio M. FHITproteasome degradation caused by mitogenic stimulation of the EGF receptor family in cancer cells. Proc Natl Acad Sci U S A. 2006; 103:18981-18986.

4. Semba S, Trapasso F, Fabbri M, McCorkell KA, Volinia S, Druck T, Iliopoulos D, Pekarsky Y, Ishii H, Garrison PN, Barnes LD, Croce CM, Huebner K. Fhit modulation of the Akt-survivin pathway in lung cancer cells: Fhit-tyrosine 114 (Y114) is essential. Oncogene. 2006; 25:2860-2872.

5. Weiske J, Albring KF, Huber O. The tumor suppressor Fhit acts as a repressor of beta-catenin transcriptional activity. Proc Natl Acad Sci U S A. 2007; 104:20344-20349.

6. Gaudio E, Paduano F, Spizzo R, Ngankeu A, Zanesi N, Gaspari M, Ortuso F, Lovat F, Rock J, Hill GA, Kaou M, Cuda G, Aqeilan RI, et al. Fhit delocalizes annexin a4 from plasma membrane to cytosol and sensitizes lung cancer cells to paclitaxel. PLoS One. 2013; 8:e78610.

7. Semba S, Huebner K. Protein expression profiling identifies cyclophilin A as a molecular target in Fhit-mediated tumor suppression. Mol Cancer Res. 2006; 4:529-538.

8. Kelley K, Berberich SJ. FHIT gene expression is repressed by mitogenic signaling through the PI3K/AKT/FOXO pathway. Am J Cancer Res. 2011; 1:62-70.

9. Romero I, Martinez M, Garrido C, Collado A, Algarra I, Garrido F, Garcia-Lora AM. The tumour suppressor Fhit positively regulates MHC class I expression on cancer cells. J Pathol. 2012; 227:367-379.

10. Boylston JA, Brenner C. A knockdown with smoke model reveals FHIT as a repressor of Heme oxygenase 1. Cell Cycle. 2014; 13:2913-2930.

11. Kitahashi T, Tsujiuchi T, Satoh K, Ohtsuki K, Konishi Y, Tsutsumi M. Aberrant transcription of FHIT gene in intrahepatic cholangiocellular carcinomas induced by $\mathrm{N}$-nitrosobis (2-oxopropyl) amine in hamsters. Exp Toxicol Pathol. 2004; 56:153-157. 
12. Zanesi N, Fidanza V, Fong LY, Mancini R, Druck T, Valtieri M, Rüdiger T, McCue PA, Croce CM, Huebner K. The tumor spectrum in FHIT-deficient mice. Proc Natl Acad Sci U S A. 2001; 98:10250-10255.

13. Vecchione A, Sevignani C, Giarnieri E, Zanesi N, Ishii H, Cesari R, Fong LY, Gomella LG, Croce CM, Baffa R. Inactivation of the FHIT gene favors bladder cancer development. Clin Cancer Res. 2004; 10:7607-7612.

14. D'Arca D, LeNoir J, Wildemore B, Gottardo F, Bragantini E, Shupp-Byrne D, Zanesi N, Fassan M, Croce CM, Gomella LG, Baffa R. Prevention of urinary bladder cancer in the FHIT knock-out mouse with Rofecoxib, a Cox-2 inhibitor. Urol Oncol. 2010; 28:189-194.

15. Zanesi N, Mancini R, Sevignani C, Vecchione A, Kaou M, Valtieri M, Calin GA, Pekarsky Y, Gnarra JR, Croce CM, Huebner K. Lung cancer susceptibility in Fhit- deficient mice is increased by Vhl haploinsufficiency.Cancer Res. 2005; 65:6576-6582.

16. Fujishita T, Doi Y, Sonoshita M, Hiai H, Oshima M, Huebner K, Croce CM, Taketo MM. Development of spontaneous tumours and intestinal lesions in Fhit gene knockout mice. Br J Cancer. 2004; 91:1571-1574.

17. Chang TM, Li XM, Fan YY. Correlation between expression of FHIT protein in gastric polyps and gastric cancer and Helicobacter pylori infections. Chin J Nosocomiol. 2013; 23:2395-2397.

18. Guo XQ, Huang XS, Lin XY, Zheng W, Chen L, Li R, Jiang YY. Expression and significance of FHIT and PTEN in gastric carcinoma. Acd J PLA Postgrad Med Sch. 2006; 27:468-470.

19. Li DX, Wang YL, Feng YL. PTEN and FHIT expressions in gastric cancer and their clinical significance. Shiyong Yixue zazhi. 2009; 25:3956-3958.

20. Li YZ, Zhao P. Expressions of cyclinB1, FHIT and Ki-67 in 336 gastric carcinoma patients and their clinicopathologic significance. Zhonghua Yi Xue Za Zhi. 2009; 89:2337-2341.

21. Ma YY, Zhang ZX, Yuan BL, Chen SQ. Expression of FHIT and WWOX in gastric cancer tissues and its relationship with clinicopathological characteristics. Prac J Cancer. 2011; 26:600-602.

22. Skopelitou AS, Mitselou A, Katsanos KH, Alexopoulou V, Tsianos EV. Immunohistochemical expression of Fhit protein in Helicobacter pylori related chronic gastritis, gastric precancerous lesions and gastric carcinoma: correlation with conventional clinicopathologic parameters. Eur J Gastroenterol Hepatol. 2003; 15:515-523.

23. Yang Y. Expression of FHIT and Smad4 in gastric carcinoma and its relationship with prognosis. J Qiqihar University Med. 2016; 37:2509-2511.

24. Zhao P, Liu W, Lu YL. Clinicopathological significance of FHIT protein expression in gastric adenocarcinoma patients. World J Gastroenterol. 2005; 11:5735-5738.

25. Zheng H, Takahashi H, Murai Y, Cui Z, Nomoto K, Tsuneyama K, Takano Y. Low expression of FHIT and
PTEN correlates with malignancy of gastric carcinomas: tissue-array findings. Appl Immunohistochem Mol Morphol. 2007; 15:432-440.

26. Zhu SZ, Xiang FG, Li H. FHIT protein expression in gastric cancer and its relation with helicobacter pylori infection. Acta Acdemiae Med Qindao Univ. 2009; 45:119-121.

27. Hara A, Yashima K, Yasugi A, Koda M, Kawaguchi K, Harada K, Andachi H, Shiota G, Ito H, Murawaki Y. Expression of Fhit, Mlh1, p16INK4A and E-cadherin in early gastric neoplasia: Correlation with histological grade and gastric phenotype. Oncol Rep. 2007; 18:553-559.

28. Kawaguchi K, Yashima K, Koda M, Tsutsumi A, Kitaoka S, Andachi H, Hosoda A, Kishimoto Y, Shiota G, Ito H, Murawaki Y. Fhit expression in human gastric adenomas and intramucosal carcinomas: correlation with Mlh1 expression and gastric phenotype. Br J Cancer. 2004; 90:672-677.

29. Wang P, Liu DC, Yao M, Zhang Q, Lu LC. Study on the expression of fragile histidine triad in gastric carcinoma. Clin Dig Dis J. 2002; 14:57-59.

30. Bragantini E, Barbi S, Beghelli S, Moore PS, de Manzoni G, Roviello F, Tomezzoli A, Vindigni C, Baffa R, Scarpa A. Loss of Fhit expression is associated with poorer survival in gastric cancer but is not an independent prognostic marker. J Cancer Res Clin Oncol. 2006; 132:45-50.

31. Czyzewska J, Guzińska-Ustymowicz K, Pryczynicz A, Kemona A, Bandurski R. Immunohistochemical assessment of Fhit protein expression in advanced gastric carcinomas in correlation with Helicobacter pylori infection and survival time. Folia Histochem Cytobiol. 2009; 47:47-53.

32. Capuzzi D, Santoro E, Hauck WW, Kovatich AJ, Rosato FE, Baffa R, Huebner K, McCue PA. Fhit expression in gastric adenocarcinoma: correlation with disease stage and survival. Cancer. 2000; 88:24-34.

33. Rocco A, Schandl L, Chen J, Wang H, Tulassay Z, McNamara D, Malfertheiner P, Ebert MP. Loss of FHIT protein expression correlates with disease progression and poor differentiation in gastric cancer. J Cancer Res Clin Oncol. 2003; 129:84-88.

34. Zheng HC, Li XH, Hara T, Masuda S, Yang XH, Guan YF, Takano Y. Mixed-type gastric carcinomas exhibit more aggressive features and indicate the histogenesis of carcinomas. Virchows Arch. 2008; 452:525-534.

35. Zheng HC, Zheng YS, Xia P, Xu XY, Xing YN, Takahashi $\mathrm{H}$, Guan YF, Takano Y. The pathobiological behaviors and prognosis associated with Japanese gastric adenocarcinomas of pure WHO histological subtypes. Histol Histopathol. 2010; 25:445-452.

36. Bria E, De Manzoni G, Beghelli S, Tomezzoli A, Barbi S, Di Gregorio C, Scardoni M, Amato E, Frizziero M, Sperduti I, Corbo V, Brunelli M, Bersani S, et al. A clinical-biological risk stratification model for resected gastric cancer: prognostic impact of Her2, Fhit, and APC expression status. Ann Oncol. 2013; 24:693-701. 
37. Lee HS, Lee HK, Kim HS, Yang HK, Kim WH. Tumour suppressor gene expression correlates with gastric cancer prognosis. J Pathol. 2003; 200:39-46.

38. Zuo H, Chan GP, Zhu J, Yeung WW, Chan AS, Ammer H, Wong YH. Activation state-dependent interaction between Gaq subunits and the Fhit tumor suppressor. Cell Commun Signal. 2013; 11:59.

39. Golebiowski F, Szulc A, Szutowicz A, Pawelczyk T. Ubc9induced inhibition of diadenosine triphosphate hydrolase activity of the putative tumor suppressor protein Fhit. Arch Biochem Biophys. 2004; 428:160-164.

40. Shi Y, Zou M, Farid NR, Paterson MC. Association of FHIT (fragile histidine triad), a candidate tumor suppressor gene, with the ubiquitin-conjugating enzyme hUBC9. Biochem J. 2000; 352:443-448.

41. Lee TG, Jeong EH, Kim SY, Kim HR, Kim H, Kim CH. Fhit, a tumor suppressor protein, induces autophagy via 14$3-3 \tau$ in non-small cell lung cancer cells. Oncotarget. 2017; 8:31923-31937. https://doi.org/10.18632/oncotarget.16652.

42. Suh SS, Yoo JY, Cui R, Kaur B, Huebner K, Lee TK, Aqeilan RI, Croce CM. FHIT suppresses epithelialmesenchymal transition (EMT) and metastasis in lung cancer through modulation of microRNAs. PLoS Genet. 2014; 10:e1004652.

43. Zandi R, Xu K, Poulsen HS, Roth JA, Ji L. The effect of adenovirus-mediated gene expression of FHIT in small cell lung cancer cells. Cancer Invest. 2011; 29:683-691.

44. Joannes A, Grelet S, Duca L, Gilles C, Kileztky C, Dalstein V, Birembaut P, Polette M, Nawrocki-Raby B. Fhit regulates EMT targets through an EGFR/Src/ERK/Slug signaling axis in human bronchial cells. Mol Cancer Res. 2014; 12:775-783.

45. Huang Q, Liu Z, Xie F, Liu C, Shao F, Zhu CL, Hu S. Fragile histidine triad (FHIT) suppresses proliferation and promotes apoptosis in cholangiocarcinoma cells by blocking PI3K-Akt pathway. Sci World J. 2014; 2014:179698.

46. Nakagawa Y, Akao Y. Fhit protein inhibits cell growth by attenuating the signaling mediated by nuclear factorkappaB in colon cancer cell lines. Exp Cell Res. 2006; 312:2433-2442.

47. Kapitanović S, Čačev T, Lončar B, Catela Ivković T, Križanac Š, Pavelić K. Reduced FHIT expression is associated with tumor progression in sporadic colon adenocarcinoma. Exp Mol Pathol. 2014; 96:92-97.

48. Han Y, Zhang Z, Zhang GJ, Guo KF, Shan GY, Kong CZ. Aberrant FHIT expression is linked to bladder carcinogenesis and apoptosis. Asian Pac J Cancer Prev. 2011; 12:2915-2920.

49. Yin DT, Wang L, Sun J, Yin F, Yan Q, Shen R, He G, Gao $\mathrm{JX}$. Association of the promoter methylation and protein expression of Fragile Histidine Triad (FHIT) gene with the progression of differentiated thyroid carcinoma. Int J Clin Exp Pathol. 2010; 3:482-491.

50. Zheng H, Tsuneyama K, Takahashi H, Miwa S, Nomoto K, Saito H, Masuda S, Takano Y. Expression of PTEN and FHIT is involved in regulating the balance between apoptosis and proliferation in lung carcinomas. Anticancer Res. 2007; 27:575-581.

51. Huang LW, Chao SL, Chen TJ. Reduced Fhit expression in cervical carcinoma: correlation with tumor progression and poor prognosis. Gynecol Oncol. 2003; 90:331-337.

52. Kuwai T, Tanaka S, Kaio E, Hiyama T, Ito M, Kitadai Y, Sumii M, Yoshihara M, Haruma K, Chayama K. Clinical significance of Fhit expression in development of colorectal carcinoma of various macroscopic types. Int J Mol Med. $2003 ; 12: 437-442$.

53. Bai LX, Wang JT, Ding L, Jiang SW, Kang HJ, Gao CF, Chen X, Chen C, Zhou Q. Folate deficiency and FHIT hypermethylation and HPV 16 infection promote cervical cancerization. Asian Pac J Cancer Prev. 2014; 15:93139317.

54. Yin DT, Wang L, Sun J, Yin F, Yan Q, Shen RL, Gao JX, He G. Homozygous deletion but not mutation of exons 5 and 8 of the fragile histidine triad (FHIT) gene is associated with features of differentiated thyroid carcinoma. Ann Clin Lab Sci. 2010; 40:267-272.

55. Joo YH, Park SW, Jung SH, Lee YS, Nam IC, Cho KJ, Park JO, Chung YJ, Kim MS. Recurrent loss of the FHIT gene and its impact on lymphatic metastasis in early oral squamous cell carcinoma. Acta Otolaryngol. 2013; 133:992-999.

56. Zhao P, Lu Y, Zhong M, Liu L, Li B. Inverse correlation of aberrant expression of fragile histidine triad (FHIT) protein with cyclin D1 protein and prognosis in Chinese patients with cholangiocarcinoma. Acta Oncol. 2008; 47:1557-1563.

57. Cao J, Li W, Xie J, Du H, Tang W, Wang H, Chen X, Xiao W, Li Y. Down-regulation of FHIT inhibits apoptosis of colorectal cancer: mechanism and clinical implication. Surg Oncol. 2006; 15:223-233.

58. Yoon SO. Abnormal fragile histidine triad (Fhit) expression in invasive cervical adenocarcinoma: association with tumor aggressiveness. Hum Pathol. 2007; 38:326-331.

59. Sinha R, Hussain S, Mehrotra R, Kumar RS, Kumar K, Pande P, Doval DC, Basir SF, Bharadwaj M. Kras gene mutation and RASSF1A, FHIT and MGMT gene promoter hypermethylation: indicators of tumor staging and metastasis in adenocarcinomatous sporadic colorectal cancer in Indian population. PLoS One. 2013; 8:e60142.

60. Tan S, Sun C, Wei X, Li Y, Wu Y, Yan Z, Feng F, Wang J, Wu Y. Quantitative assessment of lung cancer associated with genes methylation in the peripheral blood. Exp Lung Res. 2013; 39:182-190.

61. Chen X, Li P, Yang Z, Mo WN. Expression of fragile histidine triad (FHIT) and WW- domain oxidoreductase gene (WWOX) in nasopharyngeal carcinoma. Asian Pac J Cancer Prev. 2013; 14:165-171.

62. Younes SF, Aiad HA, Asaad NY, Kandil MA, Natkunam Y, Mokhtar NM. FHIT, EGFR, and MSH2: possible 
etiopathologic, prognostic, and predictive role in nonsmall cell lung carcinoma in Egyptian patients. Appl Immunohistochem Mol Morphol. 2014; 22:275-283.

63. Tai SK, Lee JI, Ang KK, El-Naggar AK, Hassan KA, Liu D, Lee JJ, Ren H, Hong WK, Mao L. Loss of Fhit expression in head and neck squamous cell carcinoma and its potential clinical implication. Clin Cancer Res. 2004; 10:5554-5557.

64. Chen PM, Yang MH, Hsiao LT, Yu IT, Chu CJ, Chao TC, Yen CC, Wang WS, Chiou TJ, Liu JH. Decreased FHIT protein expression correlates with a worse prognosis in patients with diffuse large B-cell lymphoma. Oncol Rep. 2004; 11:349-356.

65. Toledo G, Sola JJ, Lozano MD, Soria E, Pardo J. Loss of FHIT protein expression is related to high proliferation, low apoptosis and worse prognosis in non-small-cell lung cancer. Mod Pathol. 2004; 17:440-448.

66. Takizawa S, Nakagawa S, Nakagawa K, Yasugi T, Fujii T, Kugu K, Yano T, Yoshikawa H, Taketani Y. Abnormal Fhit expression is an independent poor prognostic factor for cervical cancer. Br J Cancer. 2003; 88:1213-1216.

67. Ramp U, Caliskan E, Ebert T, Karagiannidis C, Willers R, Gabbert HE, Gerharz CD. FHIT expression in clear cell renal carcinomas: versatility of protein levels and correlation with survival. J Pathol. 2002; 196:430-436.

68. Lee JI, Soria JC, Hassan K, Liu D, Tang X, El-Naggar A, Hong WK, Mao L. Loss of Fhit expression is a predictor of poor outcome in tongue cancer. Cancer Res. 200; 61:837-841. 